\title{
Exchange Rate Regimes in the Modern Era: \\ Fixed, Floating, and Flaky
}

\author{
Andrew K. Rose ${ }^{1}$ \\ UC Berkeley, NBER and CEPR \\ Haas School of Business, CA 94720-1900 \\ Tel: (510) 642-6609 E-mail: arose@haas.berkeley.edu \\ June 1, 2011
}

\begin{abstract}
This paper provides a selective survey of the incidence, causes, and consequences of a country's choice of its exchange rate regime. I begin with a critical review of Klein and Shambaugh's (2010) book Exchange Rate Regimes in the Modern Era, and then proceed to provide an alternative overview of what the economics professions knows and needs to know about exchange rate regimes. While a fixed exchange rate with capital mobility is a welldefined monetary regime, floating is not; thus, it is unclear whether it is theoretically sensible to compare countries across exchange rate regimes. This comparison is quite difficult to make empirically. It is often hard to figure out what the exchange rate regime of a country is in practice, since there are multiple conflicting regime classifications. More importantly, similar countries choose radically different exchange rate regimes without substantive consequences for macroeconomic outcomes like output growth and inflation. That is, the profession knows surprisingly little about either the causes or consequences of national choices of exchange rate regimes. But since the consequences of these choices are small, understanding their causes is of only academic interest.
\end{abstract}

JEL Classification Numbers: F33, E58

Keywords: monetary, policy, government, flexible, cause, consequence, incidence, empirical.

\footnotetext{
${ }^{1}$ I thank: the Bank of England and INSEAD for hospitality; Michael Klein, Jay Shambaugh, Alan Taylor, and the editor, Roger Gordon, for comments; and Jonathan Ostry for sharing his work and data. The data set and key output are freely available at http://faculty.haas.berkeley.edu/arose
} 


\section{What's International about International Finance?}

The exchange rate is an important asset price, perhaps the most important asset price. It's also a distinctive asset price. The price of Exxon stock or the 10-year Treasury bond rate fluctuates over time in a reasonably consistent manner. By way of contrast, the exchange rate has distinct, well-defined regimes which are chosen by the government and maintained by the central bank. No entity essentially ever attempts to peg the price of a stock or bond around a central parity with narrow fluctuation bands. ${ }^{1}$ However, some economies do fix their exchange rates (for example, Denmark, or Hong Kong), while others do not (Canada, New Zealand). A number of countries have changed their minds on the topic and switched regimes (Thailand in July 1997, Argentina in January 2002). Official authorities - at least some of them - clearly reveal through their policies that they care about the exchange rate. One would then like to understand both the motivation and the consequences of these decisions.

The fact that exchange rate policies vary across countries and time suggests that the causes and effects of exchange rate regimes can be understood both empirically and theoretically. Such is the compelling motivation for Exchange Rate Regimes in the Modern Era, a recent book by Michael Klein and Jay Shambaugh which summarizes work in the field. The focus is on the "modern era" since the Bretton Woods system (of widespread pegged exchange rates) finally collapsed in 1973 . The authors provide a simple theoretical framework for their analysis by way of an informal introduction to two of Mundell's greatest hits; his trilemma (which states that open capital markets, fixed exchange rates and monetary sovereignty are mutually incompatible), and his theory of optimum currency areas (which provides the theoretical basis for a national money). But they really seek to summarize and extend the empirical work in the area of exchange rate regimes, much of which is their own.

The book is limited, but the book is good. It is pitched at a moderate technical level, easily accessible to masters' students, advanced undergraduates, and policy-makers. The prose is clear and accessible. Most of the chapters are self-contained pieces focusing on a welldefined topic, each with elementary theory, a literature review, and new empirics. The 
coverage is both comprehensive and balanced. All this is very much to the good. This slim volume is a valuable contribution to the literature.

The book is good, but the book is limited. It does not present a new theory, data set, or methodology. Much of it is based on Mundell's celebrated 1968 textbook, and uses conventional reduced-form regressions on easily accessible data sets. This is by design and enhances the accessibility of the book, while also limiting its research potential upside.

\section{Who's What?}

Klein and Shambaugh begin their study by reviewing the classifications of exchange rate regimes. One might think that splitting the world into countries that have fixed as opposed to floating exchange rate regimes is a trivial task, but far from it. In the bad old days, the IMF provided exchange rate regime classifications based upon official statements of de jure policy intent by the national authorities; these were used widely through the late twentieth century. If Nicaragua said that it maintained a fixed exchange rate in 1990 at the height of a hyperinflation (as it did), then it was fixed according to the Fund. This was clearly an unsatisfactory state of affairs.

During the last decade, a number of exchange rate regime classifications have been developed, each of which relies on actual de facto behavior. The three best-known alternatives to de jure classifications are those developed by Levy-Yeyati and Sturzenegger (2003, hereafter "LYS"), Reinhart and Rogoff (2004, "RR") and Shambaugh (2004). Each is based on a different technique. LYS combine data on exchange rates and international reserves using cluster analysis; that way they can account for exchange market intervention as well as exchange rate movements. RR rely on the movements of market-determined exchange rates; these often diverge from official ones when there are parallel or dual markets because of capital controls. Shambaugh classifies a country as pegged if its official exchange rate remains within a small band for a sufficiently long period of time. All the methods classify nominal exchange rate regimes. 
The three systems based on de facto behavior have one striking common characteristic: all reveal that the de jure classification is untrustworthy much of the time. Many countries that state they float actually intervene to smooth the exchange rate a lot (a phenomenon known as "fear of floating"). Conversely, many countries that state they peg have a lot of inflation and capital controls so that their currencies actually trade at deep discounts on black markets. Accordingly, the profession has concluded that de facto classifications make a lot more sense than de jure ones. Indeed, the IMF has classified exchange rate regimes using a system based on actual behavior since the late 1990s (notably leading academic research by years). When it comes to exchange rate regimes, as with so many other things, the words of countries often do not correspond to their deeds.

But the differences between the three de facto systems are more apparent than their commonality. They are available for different spans of data across both countries and time (there are also gaps within LYS; the UK is not classified until 1987). Most are annual, but RR is monthly. Some have a large number of classifications - RR include fifteen - but some are simple; Shambaugh's only includes two (peg and non-peg). The systems have different levels of volatility. A country changes its exchange rate regime on average every five years according to LYS, while others show more stability; RR typically changes less than once every twenty years. And the schemes clash. While the official IMF exchange rate regime for Canada shows that it has floated since 1970, RR never classify Canada as floating. LYS show no less than nine regime switches between 1974 and 2004. In 1990, when the Bank of Canada stated officially that it was floating, the classifications ranged from floating (LYS) through a narrow crawl (RR) to peg (Shambaugh). The disagreements between the four systems are common, as shown in Table 1 below (reproduced from chapter 3 of the book).

So there are now four classifications of exchange rate regimes: official IMF, LYS, RR, and Shambaugh. Klein and Shambaugh explore the reasons that these classifications do not overlap well. As is common in economics, they conclude that the different systems are simply measuring different things, and are thus useful in different contexts. This seems to me like slipping into a warm bath when a cold shower is more appropriate; to an outsider, it is scary 
that one can no longer say with confidence that currency $x$ at time $y$ was fixed, floating or whatever.

\section{Scoring a Fix}

Klein and Shambaugh show that all four of the exchange rate regime classifications work tolerably in a precise but limited sense; countries with fixed exchange rates have lower exchange rate volatility than countries that float. One might think that this result is reassuring, perhaps to the point of banality. On the contrary; this result actually turns out to be frightening, simply because it represents one of the few features of the exchange rate regime that is observable, sensible, and robust. Floating exchange rates are more volatile than fixed ones. $^{2}$

However, when you move much beyond the simple linkage between the exchange rate regime and exchange rate volatility, you enter unknown (often enemy) territory. Perhaps the greatest disappointment is in the empirical modeling of the causes of exchange rate regimes. Klein and Shambaugh show convincingly that theories of exchange rate regime determination simply work terribly in practice. Former colonies tend to stay fixed to their colonizers and ... it's impossible to say much more with confidence. One would think that countries choose their regimes fundamentally on the basis of national characteristics that move only slowly over time (such as geographic, political, demographic, or institutional features), and indeed Klein and Shambaugh find implicit evidence for this since country fixed effects are statistically important. But they, like others, are unable to link their fixed effect estimates to observables. Of course if you want to look in just the right way with just the right measures, sample, and technique, you can find something. But positive results on regime determination have to be handled with care, since they invariably seems to die when exposed to light.

The absence of positive results is also true of the time-series dimension. While countries have historically switched their exchange rate regimes frequently, our profession has made little progress in understanding why Thailand floated the baht in July 1997 instead of 
January 1997 or July 1995. Klein and Shambaugh find some positive duration dependence in exchange rate pegs; those regimes that have survived a few years are likely to continue on. But a strong linkage between the collapse of fixes and interesting economic fundamentals - if it exists - has eluded the profession over the last twenty years despite our best efforts. This state of affairs is not the fault of the authors, but it is still depressing.

One comes to a book with certain preconceptions, and it's comforting (if not stimulating) to find out that many of these are confirmed. Indeed, much of the book essentially confirms conventional wisdom, albeit carefully, with all appropriate caveats. This is especially true when it comes to examining the consequences of exchange rate regimes, where the authors experience some empirical success, in contrast to their work on regime causes. For instance, they find that Mundell's trilemma works, but not nearly as tightly in practice as in theory; a non-trivial amount of monetary autonomy seems to remain even for countries with fixed exchange rates and open capital markets. Klein and Shambaugh estimate that when an anchor country (the USA) raised interest rates, peggers (Hong Kong) take almost eight months to adjust their own interest rates even half-way. This seems like more monetary sovereignty than most fixers experience in practice. ${ }^{3}$ More intuitively, countries that tightly link their currencies experience substantially more trade as a result; what reasonable person could dispute that? ${ }^{4}$ Peggers may also have somewhat less inflation than non-peggers, though the effect is small and uncertain. And the authors find no compelling linkage between the exchange rate regime and economic growth, consistent with monetary neutrality. All these are eminently reasonable and defensible positions, indeed, infuriatingly so for a reviewer. In this book, the authors have largely ratified what is now not only conventional wisdom but also official wisdom; most of this book fits comfortably with the IMF's view on exchange rate regimes (Ghosh et al, 2010; Rogoff et al, 2004).

Several of the strengths of the book are worth highlighting. As already mentioned, lots of the problems examined in this area have proven too thorny for economists; the area is filled with negative results. This could have resulted in considerable "publication bias," as journals tend not to be interested in negative results. The authors are to be commended for avoiding 
this selection problem in their literature reviews; one notices a large number of unpublished working papers in the references. Also, the authors attempt an admirable amount of extensive sensitivity analysis to ensure that key results are robust with respect to using different classifications of exchange rate regimes, handling simultaneity, cutting the sample by stage of development, and so forth.

That said, the choice to use Shambaugh's exchange rate regime classification scheme as the default is natural for the authors, but still seems questionable to me. This scheme classifies a country as pegged if the official exchange rate has varied by less than $+-2 \%$ over the last two years; otherwise it is non-pegged. It seems odd to distrust a country's de jure exchange rate regime data, but simultaneously to trust its de jure exchange rate data. Consider the case of Bolivia. From October 1972 through November 1979, the official exchange rate was fixed at 20.0 Bolivianos per dollar; this then rose to 24.5 through February 1982. During the same period of time there were multiple exchange rates, a fact that seems unsurprising since cumulative inflation during that period of time was approximately $600 \%$. It was just such grounds that lead RR to use black market exchange rates in their "natural" exchange rate regime classification; they classify Bolivia as "freely falling" for much of the same period. But Shambaugh's classification has it as fixed (aside from the 1979 devaluation). I'd also prefer a measure of exchange rate regimes to control explicitly for the shocks that hit the economy during the time (as do LYS). I dropped a draft of this review on the ground outside today and it didn't move. Shambaugh would classify it as pegged; I'd say that there was no wind to move it. This isn't to say that Shambaugh's classification isn't the best one available, and best is what counts. But best may not be very good.

\section{Gripes}

A fixed exchange rate policy is well-understood by bankers, practitioners, and academics around the world; one knows what the central bank does. But what's the alternative? Floating is not a well-defined monetary policy. If the central bank doesn't fix the exchange rate, it has to do something else ... but what? The academic profession should move away from considering 
"Exchange Rate Regimes" and instead classify countries by "Monetary Policy Frameworks". ${ }^{5}$ Some countries that float adhere to a clear policy of having an independent central bank target inflation (New Zealand, Sweden, Chile ...). But not all; some countries target money growth (Nigeria), and others have what can be referred to as opaque monetary policy (what is it that the Bank of Japan targets?). Is it reasonable to lump all non-fixers together? Perhaps one reason that the authors find weak results when comparing peggers with others is that the latter group is a heterogeneous mess.

A second grumble is that transitions between exchange rate regimes are essentially ignored by Klein and Shambaugh. One thing we know with confidence is that most exchange rate regimes do not remain fixed forever. When a pegger switches to a float, it often does so during a dramatic currency crisis (UK, Italy and Sweden in 1992, Mexico in 1994, Indonesia, Korea, and Thailand in 1997, Russia in 1998, Brazil in 1999, Argentina in 2002, ...). The international finance profession is somewhat obsessed by such events, which have been much studied over the last few decades, starting with seminal work by Krugman (for which, in part, he was awarded the Nobel prize). The book does cover some of this ground by using statistical hazard models to estimate probabilities that fixers will float and vice versa, but the analysis is mechanical and almost devoid of economics. Can one really compare the characteristics of exchange rate regimes while avoiding the transitions between them?

An empirically-oriented book on exchange rate regimes aimed at this audience should really provide more institutional detail, so that the reader can learn, at least superficially, how fixed exchange rate regimes work in practice. For instance, the operation of fiscal policy is dramatically affected by the exchange rate regime; in turn, fiscal policy is often constrained by the regime. This is an issue of enormous policy interest, especially in Europe and Latin America. However "fiscal" does not even enter the index of the book. More importantly, there should be more descriptive history of the evolution of the international monetary system. The "modern era" of exchange rate regimes includes a large number of distinct exchange rate regimes which go unmentioned by the authors: 
- The Latin pegs that were key to the disinflation programs of Argentina, Brazil, Chile, and others.

- The implicit Asian pegs of the 1990s that existed during the run-up to the crisis of 199798.

- The enduring pegs which continue to define the exchange rate regimes of Central-, Western- and Southern-Africa.

- The ongoing system of fixed exchange rates in Europe; all entrants to the Eurozone are required to remain fixed to the Euro for at least two years before accession.

- Finally, some of the current floats are quite "clean" with a large number of countries targeting inflation and abstaining from foreign exchange intervention almost obsessively (New Zealand, Canada, and the UK).

I try to fill in some of these gaps below.

Finally, there is the scope of the exercise. To me, most seriously fixed exchange rates (such as those of Denmark, Hong Kong, or Latvia) seem too constraining to be worthwhile; why not go all the way to currency union and give up monetary sovereignty (as countries do when they join the euro)? On the other hand, floating exchange rates seem far more volatile than any reasonable model would indicate, and this volatility seems undesirable and unnecessary. How then should one choose in practice between fixing and floating? Such questions are not clearly answered in this book; indeed they are not even asked. This is not because they ignore some large segment of the literature; the literature has little of value to say.

\section{The Authors' Trilemma}

Any book that seeks to conduct a scholarly review and extension of a broad topic, as this one does, faces a trilemma: it can be comprehensive, balanced, or interesting, but not all three. Suppose it is balanced and compelling, providing a single coherent and interesting viewpoint in a fair-minded way. In this case, it simply cannot be a comprehensive review of all the relevant territory, since discordant notes will inevitably have been omitted. On the other hand, a book 
may be comprehensive and interesting, but then it cannot be impartial; evidence must be unfairly discounted to ensure that everything fits into a single mindset. Klein and Shambaugh have chosen the first two desirable characteristics, and their book is both impartial and complete. Sadly, this comes at the cost of excitement and clarity; the weak results and caveats tend to leave the reader with mush.

Exchange Rate Regimes in the Modern Era is a wide-ranging and fair-minded but bland book. Did the authors make the right choice in the trilemma? I think that the answer is probably yes; the book fills a gap in the literature. So the authors have done a service to the profession by providing us with this book. Still, the balance and scope of the endeavor comes at the cost of presenting a single gripping viewpoint; the authors tend to eschew black and white when grey will suffice. Two Cheers!

\section{The Fix We're In}

I proceed now by following the layout of the book, but deliberately give up any attempt at being comprehensive. I begin with a selection of some of the grosser stylized facts that we know about the incidence of exchange rate regimes; these findings are complementary to those presented by Klein and Shambaugh. I then discuss both the causes and consequences of exchange rate regimes. I conclude by moving the discussion up a level, and questioning whether the habitual call for further research is warranted in this case.

\section{6a. The Importance of Different Exchange Rate Regimes}

Many countries in the world maintain fixed exchange rates, indeed, usually a majority of them (though this depends on time and the exact classification scheme). The prevalence of fixes seems clear from Figure 1, which splits up the countries of the world into one of three exchange rate regimes (fixed, intermediate, and floating), using the four different popular classification systems. It seems clear that over the modern era, as during the preceding Bretton 
Woods era, fixing has been the exchange rate regime of choice. Many, if not most, of the countries in the world fix their exchange rates.

I began this review by stating that the exchange rate is an unusual asset prices in that it has official regimes of volatility. But it is also unusual in another respect; it is the most heavily traded asset price. The most recent reliable data we have on foreign exchange turnover was collected in April 2010. The BIS reports in its Triennial Survey that at that point average daily turnover was approximately $\$ 4.0$ trillion. By way of comparison, daily turnover on the twelve deep stock and derivative exchanges collectively operated by NYSE Euronext in April 2010 was an order of magnitude lower at approximately $\$ 75$ billion. $^{6}$

The volume of trading in foreign exchange markets is closely linked to the exchange rate regime, since almost all the activity occurs between currencies that are floating. Table B.6 of the 2007 BIS report shows that more than $97 \%$ of turnover was generated between pairs of floating currencies. ${ }^{7}$ More generally, a bunch of the countries with fixed exchange rate regimes just aren't that big. Figure 2 divides global GDP (taken from the Penn World Table 6.3) into different exchange rate regimes. Where Figure 1 splits countries into different regimes, Figure 2 looks at the distribution of real output across regimes. It also uses currencies instead of countries as the unit of measurement, since a number of countries are in currency unions and so do not have a national money (sixteen countries currently use the Euro, which floats). The message from Figure 2 is quite different from that of Figure 1. During the modern era, only a small fraction of world output has been produced in economies with fixed rates. It is easy to overstate the real importance of fixed exchange rate regimes. ${ }^{8}$

\section{6b. Regime Durability}

Another striking fact about exchange rate regimes is that they have become more persistent. Starting in the 1990s, the world saw a series of wild currency crises, beginning with the European Currency Crisis of 1992-93 and culminating in the Argentine devaluation of 2002. But there has not been a currency crisis of comparable importance since, despite the global 
"Great Recession" of 2008-09. Figure 3 shows the proportion of global GDP in economies that have changed their exchange rate regimes during the past year. The message of Figure 3 is clear; switches in exchange rate regimes have now become rare. Part of the reason why economists like Klein and Shambaugh no longer study currency crises much is that they're becoming history.

\section{6c. Does Size Matter?}

It is easy to think that a country's size (population) affects its choice of exchange rate regime, but difficult to imagine the opposite. Creating and maintaining a central bank with its own monetary policy is a cost, one that will weigh more heavily on a small economy.

Many economies with fixed exchange rates are, in fact, small. Then again, there are an awful lot of small economies. Berkeley California has a larger population than 49 of the 237 "countries and other entities" listed on the CIA's widely used World Factbook, many of which are included in the various exchange rate classifications (I refer to these all as "countries" for convenience). Still, there is no doubt that the smallest countries of the world do not have floating currencies. (Indeed, a large number of the minnows don't even have their own currencies; at the time this paper was written, 95 of the CIA's listed countries did not have a currency of their own.) But one can overstate this argument; countries do not have to be very large at all before creating a floating currency. Small countries that do not fix include: the Seychelles (population 88,000 in June 2010), Tonga $(123,000)$, and Sao Tome and Principe $(176,000)$.

Figure 4 compares the size distribution of fixers and non-fixers in 2004 (the last year for which the LYS and Shambaugh data are available). It graphs the quantiles of log-population for fixers in 2004 (on the $y$-axis) against comparable data for non-fixers (on the $x$-axis). A diagonal line is provided for reference; if population were similarly distributed across fixers and nonfixers, the data would be plotted along the diagonal. In fact, the data are below the diagonal; fixers tend to be smaller than non-fixers. As already noted, fixing is especially popular for small 
countries. You might ask: How small? The answer is: quite small. There seems to be a kink in the data where country size starts to make much less of a difference; the vertical line marks a country size of 2.5 million people (around the size of Kuwait or Latvia). Countries much larger than that are more reluctant to fix, and when a country's population reaches the 10 million of Tunisia or Hungary, the distribution of countries is quite similar across fixers and non-fixers (look for the tick at $9.2 \approx \ln (10,000)$ on the $x$-axis). There are 135 countries with populations of greater than 2.5 million, 75 of which have more than 10 million citizens. Size seems unimportant to the exchange rate regime choice for countries with even moderately sized populations. $^{9}$

So the size of a country affects its exchange rate regime choice, but only a little. Very small countries tend to fix, but size is irrelevant for a wide range of countries. This should come as no surprise; China, the largest country in the world has (controversially) maintained a fixed exchange rate regime for years.

\section{6d. How about Income?}

It is even more difficult to find an empirical link between a country's income and its exchange rate regime. Some of the richest countries in the world maintain fixed rates (Brunei, Qatar), while others float (Norway, the United States). Similarly there are extremely poor countries that float (DR Congo, Burundi), but some fix (Central African Republic, Guinea-Bissau). This stylized fact is general, as shown in Figure 5. Figure 5 is the analogue to Figure 4 but instead of graphing a country's population, it focuses on country real GDP per capita. The quantile plots for fixers and non-fixers lie close to the diagonal line, indicating that there are

few systematic differences between them. ${ }^{10}$ The level of a country's real income has little systematic correlation with its exchange rate regime.

6e. More Stylized Facts 
Where economies do maintain fixed exchange rates, they are now usually fixed to one of two major anchor currencies: the American dollar or the Euro. ${ }^{11}$ The attractions of the dollar are particularly strong. According to the most recent IMF data, 66 economies (out of 192 classified) used the dollar as an exchange rate anchor. It seems implausible that so many countries from so many parts of the world could be motivated to support a dollar link because of international trade.

Some small rich economies fix (Hong Kong). Some large poor countries fix (the Ukraine). But all large rich economies float. The three most important currencies in the world are the US dollar, the euro, and the Japanese yen; all float. Other largish rich economies float as well (the UK, Canada, Australia, and Switzerland), as do many of the biggest and most important emerging economies (Brazil, India, Indonesia, Korea, Mexico, Russia, and Turkey). China has a big economy and fixes; it is the exception.

Regions differ, especially among developing countries. Sub-Saharan African countries (especially former French colonies) like to peg; central Europeans and Asians do not.

Oil exporters fix. Most OPEC members maintain de jure and de facto fixed exchange rates. That is especially true of OPEC members in the Arabian Gulf, of whom a majority fix (Saudi Arabia, Qatar, United Arab Emirates).

Small Financial Centers fix. Most offshore financial centers of the world maintain fixed exchange rates. Countries like Aruba, the Bahamas, and the Caymans are small, so this is little surprise.

Inflation Targeters Float, Often Quite Cleanly. Twenty-six countries now use inflation targeting as their monetary policy framework; they often float with little intervention. Consider the exchange rate regimes of a few of the earliest converts. New Zealand began its current float in 1985 and has intervened once since (in June 2007). Canada last intervened in the foreign exchange markets in 1998. Chile floated in 1999 and has only intervened rarely since. The UK has not intervened since the Bank of England acquired its independence in 1997. 
Nominal Exchange Rate Volatility means Real Exchange Rate Volatility. Mussa (1986) convincingly demonstrated that countries which float and accordingly experience more nominal exchange rate volatility also have more real exchange rate volatility. This characterization has been corroborated by others (Baxter and Stockman, 1989), and never seriously challenged for low-inflation economies; it is now widely accepted. It is easy to understand if nominal prices are sticky, and indeed Mussa found little difference in behavior of aggregate prices across exchange rate regimes.

\section{Summary: A Stylized Description}

A disproportionate number of the smallest countries of the world maintain fixed exchange rates. But beyond that, size has little effect on regime choice, while income has none at all. So fixed exchange rate regimes characterize a large number of countries but a small proportion of global GDP and market activity. Switches in exchange rate regimes are becoming rare. Countries that do fix tend to peg to the dollar, although the Euro also has a set of its own peggers. Oil exporters, offshore financial centers, sub-Saharan Africans, and former French colonies tend to fix; inflation targeters, former Soviet Bloc members, and large rich economies do not.

\section{Causes: How Do Countries Choose Exchange Rate Regimes?}

\section{7a. Friedman's "Daylight Savings" Argument}

Milton Friedman (1953) provided one of the most famous arguments for why all countries - at least those with low or moderate inflation - should opt for floating exchange rates. He wrote:

\footnotetext{
"The argument for flexible exchange rates is, strange to say, very nearly identical with the argument for daylight savings time. Isn't it absurd to change the clock in summer
} 
when exactly the same result could be achieved by having each individual change his habits? All that is required is that everyone decided to come to his office an hour earlier, have lunch an hour earlier, etc. But obviously it is much simpler to change the clock that guide all than to have each individual separately change his pattern of reaction to the clock, even though all want to do so. The situation is exactly the same in the exchange market. It is far simpler to allow one price to change, namely the price of foreign exchange, than to rely upon price changes in the multitude of prices that together constitute the internal price structure."

Friedman's argument is that nominal price stickiness implies that relative price adjustment is easier to achieve through nominal exchange rates than through prices. This argument is still widely seen as a powerful argument for floating exchange rates. It shouldn't be. We only adjust our clocks twice a year, by precisely one hour (unless you're in Arizona or Hawaii, in which case you don't adjust your clock at all). The one thing we know about floating exchange rates is that they are volatile, as pointed out by Mussa (1986) and Baxter and Stockman (1989). If we had to adjust our clocks by a different amount daily, we might well choose to adjust times instead of clocks.

\section{7b. National Determinants of the Exchange Rate Regime}

Theory

Mundell's trilemma implies that the real consequences of different types of shocks should, in principle, depend on the exchange rate regime. A benevolent government should choose the exchange rate regime so as to maximize its insulating effects. This leads one to the conclusion that countries experiencing a lot of real shocks should choose floating exchange rates; the presence of nominal rigidities means that relative price flexibility is easier to achieve under a float. On the other hand, countries suffering mostly from financial shocks will tend to adopt fixed rates. As Stockman (2000) writes, "the evidence supporting the predictions of these models is only slightly better than the evidence for cold nuclear fusion" so it does not seem worthwhile to pursue this line further. 
Happily, Klein and Shambaugh do not rely only on this theory. A fixed exchange rate is a transparent, easily monitored monetary anchor. As such, targeting the exchange rate might provide credibility to a young or troubled central bank. That's especially true if a country with an inflationary reputation fixes itself to the money of a foreign central bank with a reputation for low inflation (read "the Fed" or its European equivalents, the German Bundesbank and now the $E C B)$.

But perhaps not; Tornell and Velasco (2000) provide an interesting theoretical counterargument. Their view is that fixed exchange rates induce fiscal indiscipline since lax policy eventually leads to a costly collapse of the exchange rate. However, bad behavior can be manifest sooner if the exchange rate is floating and can immediately reflect unsound policy. Thus Tornell and Velasco argue that flexible exchange rates provide more discipline. Their argument is powerful since many fixed exchange rates have collapsed, often undermined by fiscal indiscipline. So political economy arguments that model imperfect monetary credibility have weak predictions for the exchange rate regime; a country with poor institutions can either fix or float. Is an exchange rate constraint always easier for a developing country to respect than another type of monetary constraint, such as an inflation target? This is clearly a matter that can only be sorted out empirically.

There are also microeconomic arguments relevant to exchange rate regime choice. Transactions costs are lowered with fixed exchange rates. It might seem hard to believe that such benefits are big, but fixes do seem to result in greater trade in practice (as chapter 9 of the book shows), and very small countries with correspondingly large trade do have a strong tendency to fix. Fixes also tend to lower the cost of foreign exchange risk, although the latter can be inexpensively hedged if the country has the appropriate set of derivative markets. And of course, a fix also decreases the incentives to reduce foreign exchange risk, so that departures from fixes might be inordinately costly.

In principle, the micro-structure of the foreign exchange market might provide an argument for official intervention to smooth or fix the exchange rate; see Guembel and Sussman (2004). This seems currently like a theoretical argument of little practical relevance. 
Governments certainly provide liquidity to the market in the course of smoothing the exchange rate and provide insurance to some of its participants; the private market also changes as a response (Killeen et al, 2006). So market microstructure may well provide a justification for intervention in poor economies with thin financial markets. But as shown above, these economies do not fix disproportionately, and their governments rarely cite micro-structure in justifying their policies. Further, some rich economies with sophisticated financial markets (like Hong Kong and Denmark) fix their exchange rates. Also, fixers do not usually intervene in other asset markets which suffer from problems similar to those of foreign exchange, such as those for equities or long bonds. The most compelling argument for the rising popularity of microstructure arguments is not that they seem plausible, but that macroeconomic models are inadequate.

\section{Empirics}

If the theories for exchange rate regime determination sound a little lame, that is appropriate. It is generous to characterize the empirical performance of existing models as "poor." We currently have little understanding of the time-series variation of exchange rate regimes (why did Sweden float out of its fix in November 1992 as opposed to some other time?). Most plausible theories of exchange rate determination depend on slow-moving macroeconomic phenomena, so that it may not be that surprising that our models explain little variation over time. But our ignorance of exchange rate regime determinants across countries is downright embarrassing. One might imagine that we know why the United States floats and Estonia is fixed ... but no. Very small countries, autocracies and former colonies are more likely to fix, but these factors collectively explain little variation in exchange rate regimes. Our attempts to explain the cross-country incidence of fixed exchange rates have thus far basically failed. If one assembles a panel of data, the between-country variation explained by countryspecific fixed effects is much larger than any within-country time-series variation linked to fundamentals. For instance, the $\mathrm{R}^{2}$ in the panel regressions that Klein and Shambaugh report in chapter 5 more than triple as country fixed effects are added. But they, like others, are unable 
to link this substantial variation across countries to reasonable predictors of the exchange rate regime. The fixed effects represent features of an economy that are unobservable and cannot be modeled empirically; they reveal little of economic interest. ${ }^{12}$

Frankel (1999) states clearly that no single exchange rate regime is appropriate for all countries or at all times. The data indicate that he is right; countries make different choices. But that does not explain why it has proven impossible for our profession to determine the characteristics that lead one country to choose one regime at one point and another later on, or why different countries make different choices. The nature of how countries choose their exchange rate regimes remains essentially an empirical mystery.

\section{Consequences: Why Should We Care about Exchange Rate Regimes?}

I now turn to the consequences of exchange rate regime. Since any substantive effect

of the exchange rate regime on growth would be important, that is where I begin. ${ }^{13}$ I start with some naïve regression evidence.

In Table 2, I report coefficients when annual real GDP growth is regressed on the exchange rate regime. The data span 178 economies from 1974 through 2007. There are four rows of estimates, one for each of the four popular exchange rate regime measurement systems. For each of the four regressions, I include (but do not report) a comprehensive set of time- and country-specific fixed effects. However, no other growth determinants are included; adding controls for the savings rate, labor force growth, institutions, and so forth is likely to reduce the coefficients further. In each case, I treat the fixed exchange rate regime as the default regime, so that the top-left estimate indicates that countries which were in narrow crawl exchange rate regimes according to the IMF's classification grew some $.8 \%$ faster on average than fixers. Robust standard errors are included in parentheses.

Unfortunately no clear results emerge from this simple exercise. The four methodologies disagree on the effects of intermediate exchange rate regimes. The official IMF classification indicates that countries in narrow crawls grow significantly faster than fixers; RR 
find the opposite (a negative but insignificant result). Symmetrically, where RR find that countries in wide crawls grow significantly more slowly than fixers, the IMF classification delivers a positive but insignificant result. Both of these regimes are combined together into a single intermediate measure by LYS, who find a negative significant effect. None of the methodologies finds that floating exchange rate countries grow significantly differently from fixers. The one strong result is eminently plausible: the "Freely Falling" basket cases grouped together by RR grow significantly more slowly than fixers (or any other group for that matter). Then again, RR define freely falling regimes as those exhibiting extreme macroeconomic distress and annual inflation of over $40 \%$. It seems fair to conclude that this simple search finds little linkage between growth and the exchange rate regime. Correlation of course is not causation; here though, there is little correlation.

One could go further, for instance by adding extra controls for other growth determinants, or splitting up countries by region, stage of development, or whatever. Rogoff et al (2004), Ghosh et al (2010), and Klein and Shambaugh all pursue this strategy; none finds a strong robust effect of the exchange rate regime on growth. ${ }^{14}$ This is unsurprising. Choosing an exchange rate regime is choosing a monetary policy. As such, the exchange rate regime should have little effect on real long-term growth, and it does not appear to. As a monetary choice it might however have implications for inflation. These are examined in Table 3a, which is the analogue to Table 2 but considers (GDP deflator) inflation. ${ }^{15}$

The results of Table $3 a$ indicate that there is no clear relationship between inflation and the exchange rate regime that spans all countries, at least beyond the high inflation observations grouped together by RR in their "freely falling" category. When floats are compared simply against fixes, there is no significant difference. LYS intermediate regimes are significantly more inflationary than their fixes, and Shambaugh's non-fixers are also more inflationary than his fixers. But the IMF's classification and RR cut the data up more finely and the former (but not the latter) find that narrow crawls have significantly lower inflation than fixes, with no other significant results. These results are consistent with the literature: there is no consensus on any inflationary consequences of exchange rate regimes for typical economies. 
Some have found that splitting the sample up further by stage of development reveals a result. In particular, developing countries with low-credibility institutions might have lower inflation under pegs, as Klein, Shambaugh and others have tried to demonstrate. This seems plausible; acquiring monetary credibility is difficult, especially for poor countries. Even a positive finding in this arena would be narrow; no one believes that rich countries receive a free credibility lunch of low inflation when they adopt a fix. But the data seem to speak softly even for developing countries. The estimates of Table $3 \mathrm{~b}$ are restricted to developing countries, and show that the effect of fixed exchange rate regimes on them depends sensitively on the precise measure of the exchange rate regime. Succinctly, there is weak evidence that poor fixers inflate more slowly.

In summary, there is scant evidence that the exchange rate regime matters much for anything real. This is believable; if there were a strong, clear and important effect of the exchange rate regime on growth, it would already be part of conventional wisdom. After all, we care about such things, and there is considerable variation in monetary regimes across time and countries, so that such effects would be easily visible. ${ }^{16}$ What is perhaps more surprising is how weak are the inflationary consequences of exchange rate regimes. Results here tend to be sufficiently sensitive to the exact sample and measure of exchange rate regime that it is hard to say anything with confidence. Such weak correlations are just manifestations of what Obstfeld and Rogoff (2001, p373) call "the exchange-rate disconnect puzzle" which is: (italics in original) "the exceedingly weak relationship between the exchange rate and virtually any macroeconomic aggregates."

\section{Should We Soldier On?}

Hong Kong is a small rich Asian economy which has good institutions and is extremely open. Singapore is another Asian economy of roughly comparable size, income, institutions, and openness. Hong Kong prides itself on having rigorously maintained a fixed nominal exchange rate since 1983 through its currency board arrangement. Singapore, on the other hand, manages its monetary policy through its exchange rate. The Sing dollar has varied from 
$S \$ 2.25 / \$$ to $S \$ 1.36 / \$$ during the decades that the HK\$ has been steady at HK\$7.8/\$. Why do such similar economies choose such different approaches to monetary policy? Denmark has stayed fixed to the Euro (earlier, the Deutschemark) at the same rate since 1987. Sweden has changed its regime a number of times since then, and now has a flexible exchange rate. Finland has also changed its exchange rate regime repeatedly, and has now relinquished independent monetary policy to become a member of the Eurozone. Yet Denmark, Sweden, and Finland are broadly comparable in size, income, institutions, and openness. The examples are legion: Panama and Costa Rica are also similar but Panama has remained rigidly dollarized since 1903 while Costa Rica has switched its exchange rate regime frequently, and has now moved to a crawling peg. Such countries have made radically different monetary decisions, without obvious long-term consequences for output or inflation, and there is no sign that their regimes will converge any time soon. The fact that similar economies make completely different choices might lead one to despair; as a profession, we have collectively made little progress in understanding how countries choose their exchange rate regimes. Still, before panicking, one should first remember that such choices often seem to have remarkably little consequence. Exchange rate regimes are flaky: eccentric and unreliable.

The issue of exchange rate regimes is a fascinating question, one that will surely intrigue economists for the foreseeable future. Still, to me the truly fascinating thing about exchange rate regimes is that ... they're fascinating. They really shouldn't be. My best friend likes tea, while I prefer coffee. While this seems immaterial, one could, in principle, figure out the reasons for our preferences, and how they affect our lives. Exchange rate regimes are much the same. Governments of similar countries make different decisions on the exchange rate regime. These views appear to be strongly held and sincere, yet they seem to have neither discernible causes nor visible consequences. Perhaps it is precisely because these issues appear to be of purely academic interest that they continue to provide inspiration for our profession; the stakes could not be lower. 


\section{References}

Bank for International Settlements (2007) Triennial Central Bank Survey: Foreign Exchange and Derivatives Market Activity in 2007.

Baxter, Marianne and Alan C. Stockman (1989) "Business Cycles and the Exchange Rate Regime" Journal of Monetary Economics 23, 377-400.

Broz, J. Lawrence (2002) "Political System Transparency and Monetary Commitment Regimes" International Organization 56, 861-867.

Flood, Robert P. and Andrew K. Rose (1995) “Fixing Exchange Rates: A Virtual Quest for Fundamentals" The Journal of Monetary Economics 36(1), 3-37.

Flood, Robert P. and Andrew K. Rose (1999) "Understanding Exchange Rate Volatility without the Contrivance of Macroeconomics" Economic Journal 109(459), 660-72.

Frankel, Jeffrey A. (1999) "No Single Currency Regime is Right for All Countries or at All Times" Princeton Essays in International Finance No. 215.

Friedman, Milton (1953) "The Case for Flexible Exchange Rates" in Essays in Positive Economics (Chicago, University Press).

Ghosh. Atish R., Jonathan D. Ostry, and Charalambos Tsangarides (2010) "Exchange Rate Regimes and the Stability of the International Monetary System" IMF Occasional Paper No. 270.

Guembel, Alexander and Oren Sussman (2004) "Optimal Exchange Rates" Journal of the European Economic Association 2-6, 1242-1274.

Killeen, William P., Richard K. Lyons and Michael J. Moore (2006) "Fixed versus Flexible" Journal of International Money and Finance 25, 551-579.

Levy-Yeyati, Eduardo and Federico Sturzenegger (2003) "To Float or to Fix" American Economic Review 93(4), 1173-1193.

Mussa, Michael (1986) "Nominal Exchange Rate Regimes and the Behavior of Real Exchange Rates" Carnegie-Rochester Conference Series on Public Policy 25, 117-214.

Obstfeld, Maurice and Kenneth S. Rogoff (2001) "The Six Major Puzzles in International Macroeconomics" NBER Macroeconomics Annual 15, 339-412.

Reinhart, Carmen M. and Kenneth S. Rogoff (2004) "The Modern History of Exchange Rate Arrangements" Quarterly Journal of Economics CXIX-1, 1-48. 
Rogoff, Kenneth, Ashoka Mody, Nienke Oomes, Robin Brooks, and Aasim M. Husain (2004)

"Evolution and Performance of Exchange Rate Regimes" IMF Occasional Paper 22.

Shambaugh, Jay (2004) "The Effect of Fixed Exchange Rates on Monetary Policy" Quarterly Journal of Economics 119-1, 301-352.

Stockman, Alan C. (2000) "Exchange Rate Systems in Perspective” Cato Journal 20-1, 115-122.

Tornell, Aaron and Andres Velasco (2000) "Fixed versus Flexible Exchange Rates: Which

Provides More Fiscal Discipline?" Journal of Monetary Economics 45(2), 399-436,. 
Table 1: Coherence of Methodologies to Code Exchange Rate Regimes

\begin{tabular}{|l|c|c|c|c|}
\hline & IMF & $\begin{array}{c}\text { Levy-Yeyati \& } \\
\text { Sturzenegger }\end{array}$ & $\begin{array}{c}\text { Reinhart \& } \\
\text { Rogoff }\end{array}$ & Shambaugh \\
\hline IMF & $100 \%$ & $100 \%$ & & \\
\hline $\begin{array}{l}\text { Levy-Yeyati \& } \\
\text { Sturzenegger }\end{array}$ & $59 \%$ & $55 \%$ & $100 \%$ & \\
\hline $\begin{array}{l}\text { Reinhart \& } \\
\text { Rogoff }\end{array}$ & $59 \%$ & & & \\
\hline Shambaugh & $68 \%$ & $65 \%$ & $65 \%$ & $100 \%$ \\
\hline
\end{tabular}

Note: Taken from Table 3.3 of Klein and Shambaugh (2010). Entries are percentages of observations where different methodologies agree. All classifications are collapsed to three categories: pegged, intermediate, and floating.

Table 2: Growth Effects of Deviations from Fixed Exchange Rate Regimes

\begin{tabular}{|l|c|c|c|c|}
\hline Classification & Narrow Crawl & $\begin{array}{c}\text { Wide } \\
\text { Crawl/Managed }\end{array}$ & Float \\
\hline Official IMF & $.8^{*}$ & .5 & .2 & $(.5)$ \\
\hline Reinhart and Rogoff & $(.3)$ & $(.4)$ & .5 & $(1.2)$ \\
& -.3 & $-1.0^{*}$ & $(.5)$ & $(.6)$ \\
\hline
\end{tabular}

\begin{tabular}{|l|c|c|}
\hline & Intermediate & Float \\
\hline Levy-Yeyati and & $-1.5^{* *}$ & -.5 \\
Sturzenegger & $(.4)$ & $(.4)$ \\
\hline
\end{tabular}

\begin{tabular}{|l|c|}
\hline & Non-Peg \\
\hline Shambaugh & .3 \\
& $(.3)$ \\
\hline
\end{tabular}

Robust standard errors in parentheses; coefficients significantly different from zero at .05 (.01) level marked by one (two) asterisk(s). Country and time fixed effects included in all regressions but not recorded. Dependent variable is annual real GDP growth from the PWT 6.3. Each row represents a different OLS regression; each coefficient represents the difference between the exchange rate regime tabulated in the column head and a fixed exchange rate. 
Table 3a: Inflation Effects of Deviations from Fixed Exchange Rate Regimes

\begin{tabular}{|l|c|c|c|c|}
\hline Classification & Narrow Crawl & $\begin{array}{c}\text { Wide } \\
\text { Crawl/Managed }\end{array}$ & Float & Falling \\
\hline Official IMF & $-9.1^{* *}$ & 2.7 & 8.8 & $(6.3)$ \\
\hline Reinhart and Rogoff & $(2.1)$ & $(3.6)$ & 7.9 & $62 .^{* *}$ \\
& .4 & .8 & $(4.3)$ & $(9.6)$ \\
\hline
\end{tabular}

\begin{tabular}{|l|c|c|}
\hline & Intermediate & Float \\
\hline Levy-Yeyati and & $18.4^{* *}$ & 3.5 \\
Sturzenegger & $(3.1)$ & $(1.9)$ \\
\hline
\end{tabular}

\begin{tabular}{|l|c|}
\hline & Non-Peg \\
\hline Shambaugh & $7.3^{* *}$ \\
& $(1.8)$ \\
\hline
\end{tabular}

Robust standard errors in parentheses; coefficients significantly different from zero at .05 (.01) level marked by one (two) asterisk(s). Country and time fixed effects included in all regressions but not recorded. Dependent variable is annual GDP inflation from the PWT 6.3. All deflationary observations (GDP deflation exceeding $>10 \%$ ) have been removed, as have all countries that have experienced a hyperinflation ( $>1000 \%$ inflation). Each row represents a different OLS regression; each coefficient represents the difference between the exchange rate regime tabulated in the column head and a fixed exchange rate. 
Table 3b: Inflation Effects of Deviations from Fixed Exchange Rate Regimes in Developing Countries

\begin{tabular}{|l|c|c|c|c|}
\hline Classification & Narrow Crawl & $\begin{array}{c}\text { Wide } \\
\text { Crawl/Managed }\end{array}$ & Float & Falling \\
\hline Official IMF & 1.2 & 1.5 & 7.5 & \\
& $(8.1)$ & $(7.2)$ & $11.5)$ & \\
\hline Reinhart and Rogoff & 3.3 & 1.4 & 14.1 & $54.2^{* *}$ \\
& $(6.2)$ & $(7.2)$ & $(9.8)$ & $(13.3)$ \\
\hline
\end{tabular}

\begin{tabular}{|l|c|c|}
\hline & Intermediate & Float \\
\hline Levy-Yeyati and & $22.0^{* *}$ & $7.3^{* *}$ \\
Sturzenegger & $(4.5)$ & $(2.4)$ \\
\hline
\end{tabular}

\begin{tabular}{|l|c|}
\hline & Non-Peg \\
\hline Shambaugh & $10.7^{* *}$ \\
& $(3.0)$ \\
\hline
\end{tabular}

Robust standard errors in parentheses; coefficients significantly different from zero at .05 (.01) level marked by one (two) asterisk(s). Country and time fixed effects included in all regressions but not recorded. Dependent variable is annual GDP inflation from the PWT 6.3. All deflationary observations (GDP deflation exceeding $>10 \%$ ) have been removed, as have all countries that have experienced a hyperinflation ( $>1000 \%$ inflation). Sample restricted to countries that are not "high income" according to the World Bank and are not in the MSCl Emerging Market Index. Each row represents a different OLS regression; each coefficient represents the difference between the exchange rate regime tabulated in the column head and a fixed exchange rate. 


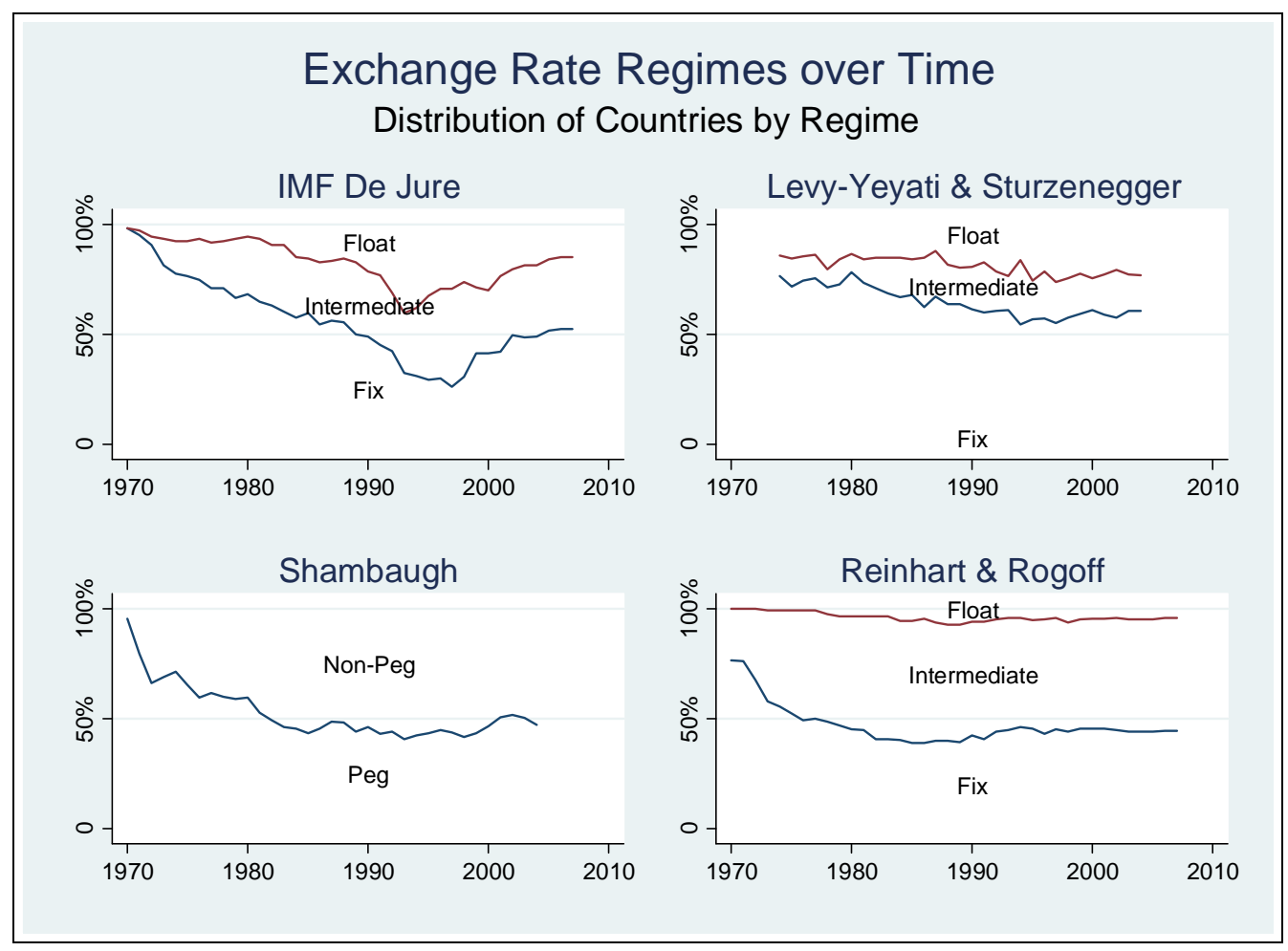

Figure 1: Dividing Countries of the World by Exchange Rate Regime

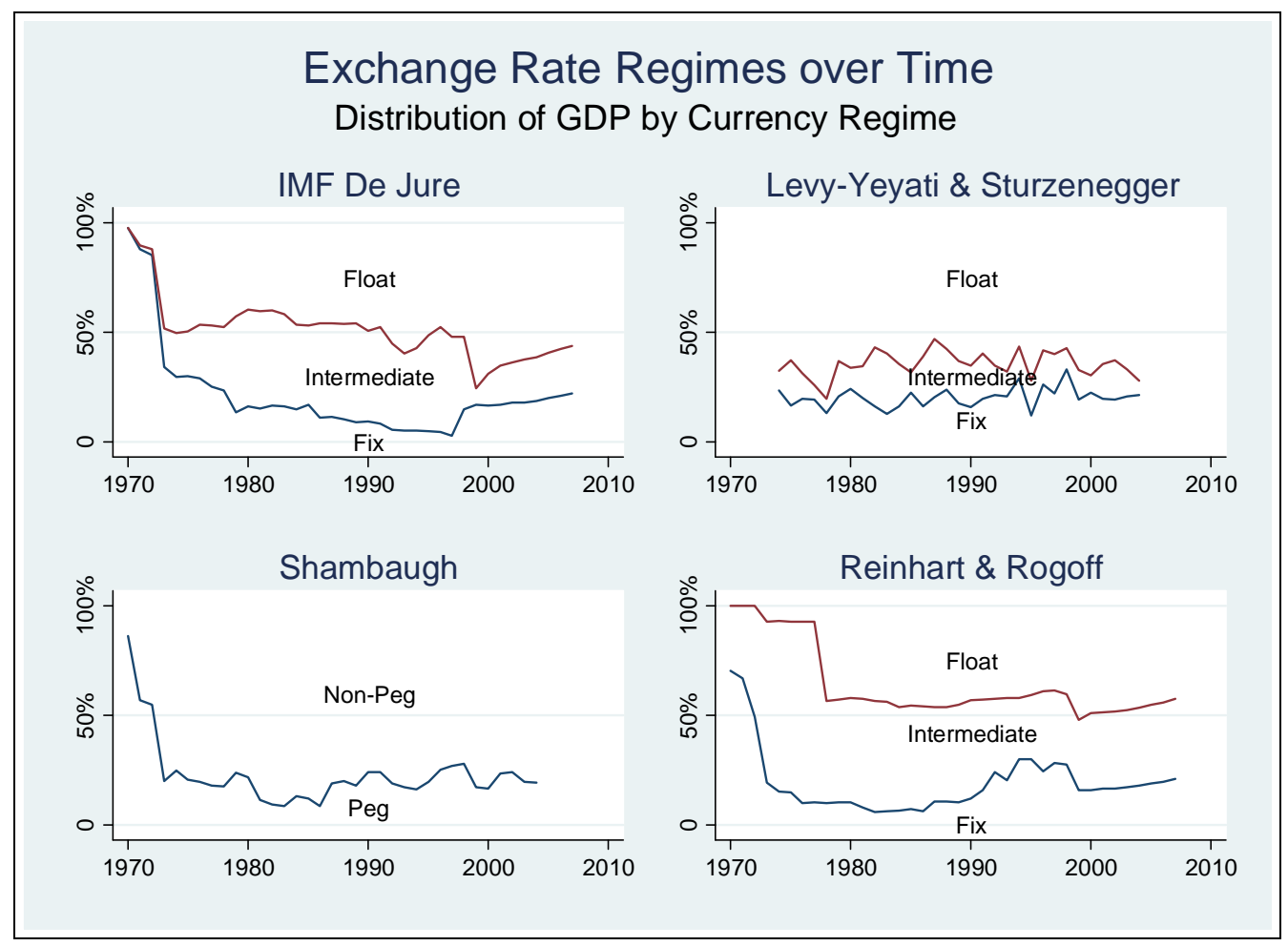

Figure 2: Dividing Output of the World by Exchange Rate Regime 


\section{Exchange Rate Regime Switches over Time}

Proportion of Global GDP in Economies with Changing Regimes
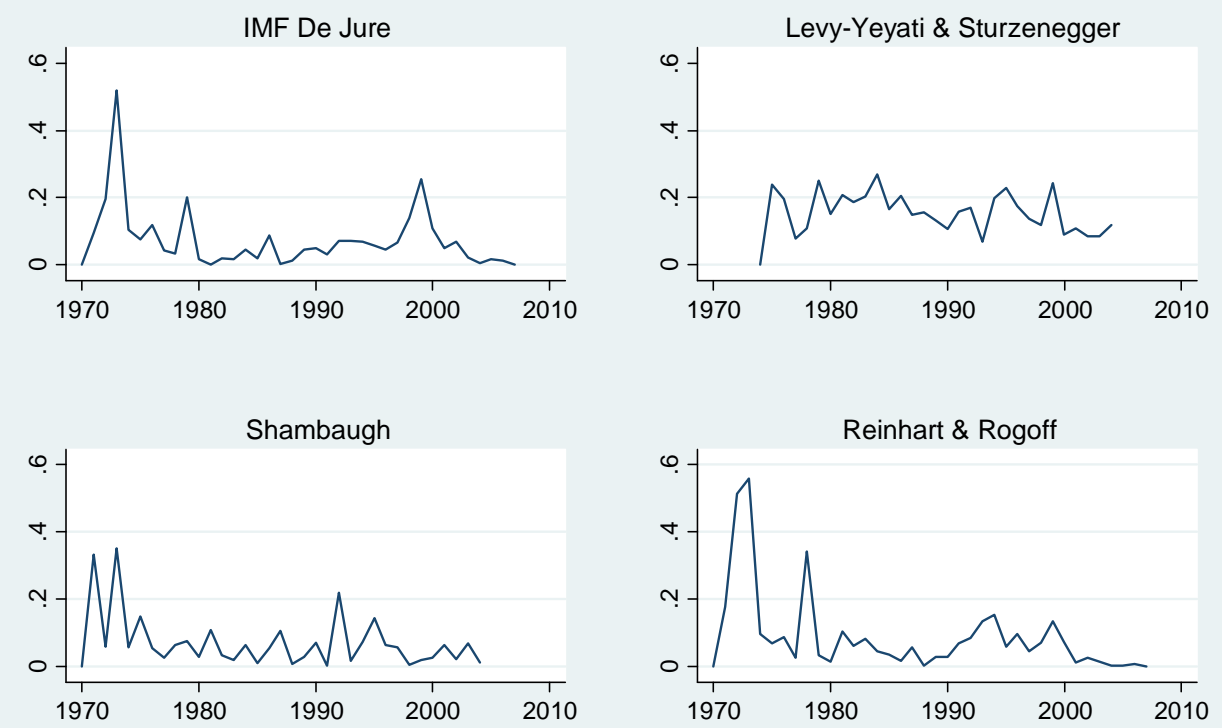

Figure 3: Dividing Output of the World by Economies with Changes in Exchange Rate Regimes

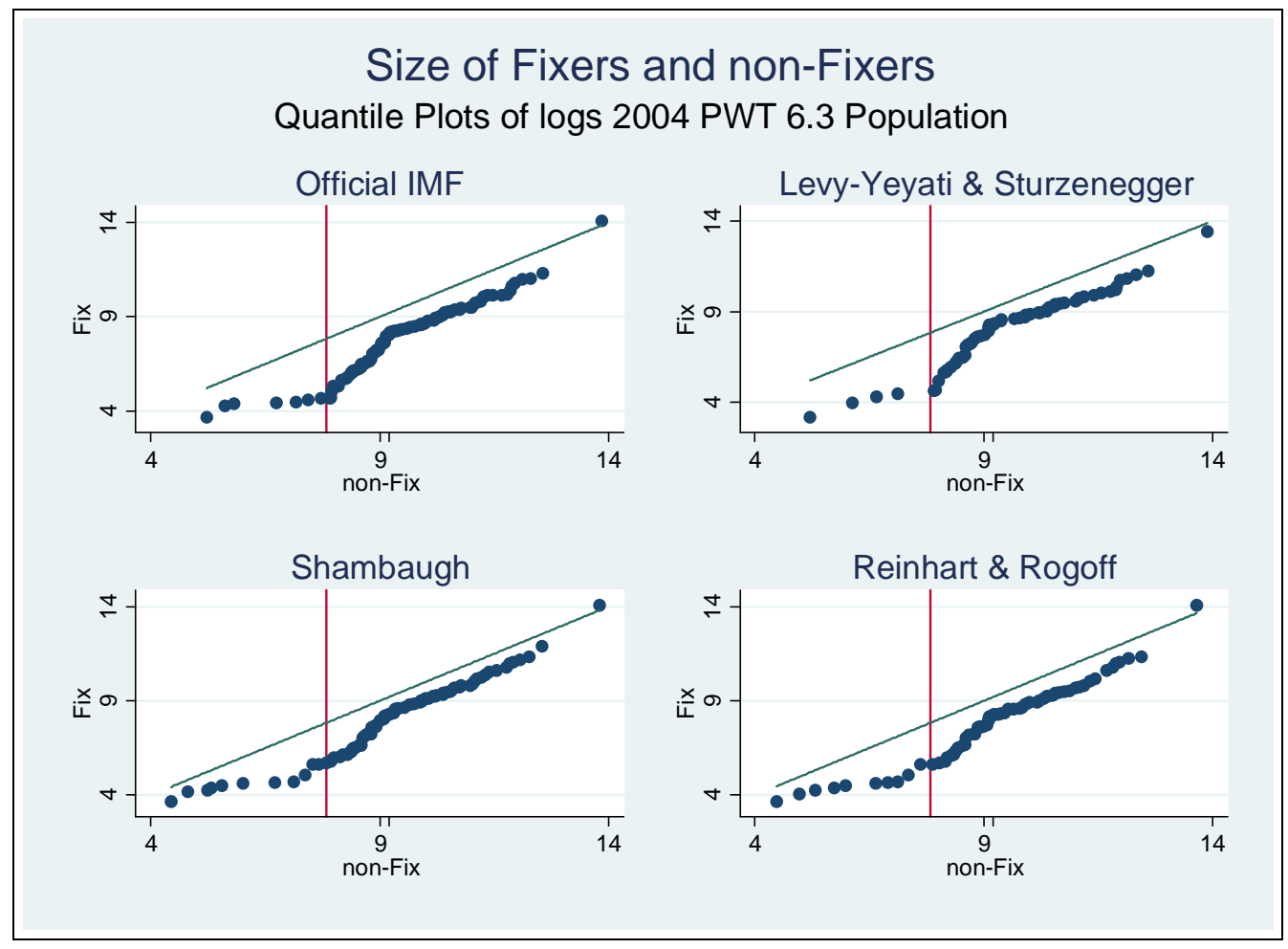

Figure 4: Who Fixes? The Size Distribution of Countries 


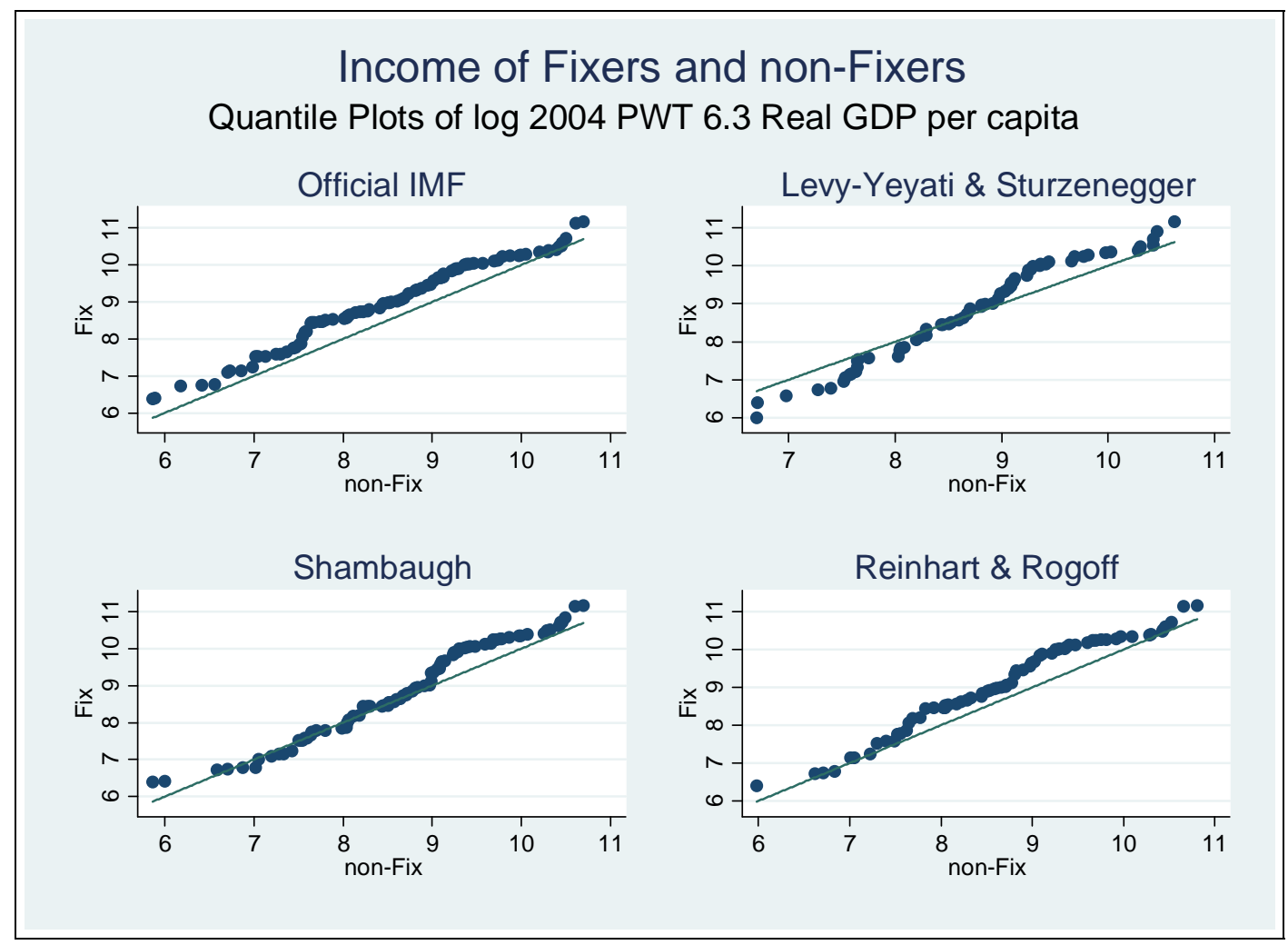

Figure 5: Who Fixes? The Income Distribution of Countries 


\section{Endnotes}

${ }^{1}$ I use "peg" and "fix" interchangeably.

2 This is not news. Mussa (1986, p117) wrote "Under a floating exchange rate regime, real exchange rates typically show much greater short term variability than under a fixed exchange rate regime. The increased variability ... is largely accounted for by the increased variability of nominal exchange rates ..."

${ }^{3}$ When Wim Duisenberg was the governor of the Dutch central bank he earned the nickname "Mr. Fifteen Minutes" because he quickly followed any interest rate changes made by the Germans.

4 Some actually; check out Klein, Michael W. (2005) "Dollarization and Trade" Journal of International Money and Finance 24-6, 935-943.

${ }^{5}$ In doing so, we would catch up with the IMF, which has done this for years; http://www.imf.org/external/np/mfd/er/index.asp.

${ }^{6}$ http://www.nyxdata.com/nysedata/asp/factbook/viewer_edition.asp?mode=table\&key=3133\&category=3

7 The comparable times are not yet available for the 2010 survey. However, the data available from the BIS, particularly Table s 3 and 4 (available at http://www.bis.org/publ/rpfx10.htm) indicate that over $95 \%$ of FX activity is still between pairs of floating exchange rates.

8 If you squint at the top left diagram of Figure 1 in just the right way, you might pick out a tendency for the de jure intermediate exchange rate regimes to shrink through the late 1990s. This was known as the problem of the "disappearing middle," a much-discussed idea at the turn of the century. However, the signs of the disappearing middle seem to vanish themselves when one uses a de facto classification scheme, as shown by the other graphs in the figure. Perhaps more importantly, most of the economy simply isn't in intermediate regimes, if one weights by GDP, as shown in Figure 2.

9 Accordingly, it is little surprise that the effect of country size on its exchange rate regime is usually insignificant in statistical exercises. Klein and Shambaugh find size statistically insignificant at the $5 \%$ level in sixteen of their nineteen regressions in chapter 5.

10 This fact can also be corroborated more rigorously with Kolmogorov-Smirnov tests, which do not reject the equality of income distribution across exchange rate regimes at standard confidence levels.

11 Before the Euro came into existence, a large number of African countries were fixed to the French Franc, which was in turn fixed to the German Deutschemark, the previous European monetary anchor.

12 One exception in this otherwise bleak set of results is the fact that more autocratic countries are more likely to have fixed exchange rates; Broz (2002). However, this statistically significant explains relatively little of the underlying variation.

${ }^{13}$ In the statistical work which follows, I temporarily treat the exchange rate regime as exogenous. This does not seem unreasonable, since exchange rate regimes seem to be distributed randomly in practice, as shown in the previous section. 
${ }^{14}$ A different tack would be to examine macroeconomic volatility, since one might think exchange rate regimes are strongly associated with business cycle shocks and their propagation. However, many authors including Baxter and Stockman $(1989)$ and Flood and Rose $(1995,1999)$ have found that there is essentially no observable relationship between the exchange rate regime and macroeconomic volatility. Consistent with this, in their celebrated $>400$ page book This Time is Different (2009, Princeton University Press) Reinhart and Rogoff (the creators of the RR exchange rate regime methodology) essentially never use data on the exchange rate regime in their comprehensive study of financial crises.

${ }^{15}$ The sample is restricted somewhat; all deflationary observations (where GDP deflation exceeding $>10 \%$ ) have been removed, as have all countries that have experienced a hyperinflation (>1000\% inflation) in the sample.

${ }^{16}$ Consider a different question: why are certain countries rich? We know that richer countries tend to have better institutions, are more open, are farther from the equator, and so forth. There is much dispute about whether such correlations are causal, and which ones dominate, but the point is that correlations that are strong and robust are worth fighting over. If any such correlations existed for exchange rate regimes, they'd be wellknown. 